\title{
A tecnologia como possibilidade de inovação na educação
}

\section{Technology as a possibility for innovation in education}

La tecnología como posibilidad de innovación en la educación

Noeli Burile ${ }^{1}$; Cleide Teresinha de Moraes Veruck²; Adriano Canabarro Teixeira ${ }^{3}$

\section{RESUMO}

As tecnologias digitais são ferramentas que apontam para a qualificação de processos educativos na educação básica, podendo, inclusive, permitir inovação nesse nível de ensino. Desse modo, o presente trabalho de intervenção pedagógica ocorreu com o objetivo de trabalhar com os docentes a motivação e a mudança de visão em relação à importância do uso das metodologias ativas no processo educativo, por meio do uso das tecnologias, despertando-Ihes para a busca do conhecimento e da atualização profissional. Para atender esse intuito, desenvolveu-se um trabalho baseado nas propostas de metodologias ativas, de forma remota, por meio do Google Meet, na qual se realizou quatro horas de oficina, dividida em dois momentos de duas horas cada, com um grupo de 13 professores atuantes em escola de ensino fundamental de um município do interior de Santa Catarina (SC). Nesses momentos utilizou-se ferramentas de forma que os docentes pudessem participar ativamente de todas as etapas da formação. Como resultados, compreendeu-se que a utilização de tecnologias na sala de aula ainda é vista como empecilho por vários docentes que participaram da intervenção. No entanto, observou-se que esses aumentaram a percepção da importância da introdução de metodologias diversificadas, aliadas à utilização de meios tecnológicos, para aprimorar o fazer pedagógico da realidade do aluno e qualificálo.

Palavras-chave: Inovação; Educação escolar; Tecnologias; Metodologias Ativas.

\begin{abstract}
Digital technologies are tools that point to the qualification of educational processes in basic education, and may even allow innovation at this level. Thus, this pedagogical intervention work was carried out with the objective of working with teachers to motivate them and change their vision in relation to the importance of using active methodologies in the educational process, through the use of technologies, awakening in them the search for knowledge and professional updating. To meet this objective, a work based on the proposals of active methodologies was developed, remotely, through Google Meet, in which a four-hour workshop was conducted, divided into two moments of two hours each, with a group of 13 teachers working in an elementary school in a city in the countryside of Santa Catarina (SC). In these moments, tools were used so that the teachers could actively participate in all stages of the training. As results, it was understood that the use of technology in the classroom is still seen as an obstacle by several teachers who participated in the intervention. However, it was observed that they have increased their perception of the importance of the introduction of
\end{abstract}

${ }^{1}$ Acadêmica do curso de Especialização em Inovação na Educação da Universidade do Oeste de Santa Catarina (UNOESC), Joaçaba/SC - Brasil. E-mail: noeliburile@gmail.com

${ }^{2}$ Acadêmica do curso de Especialização em Inovação na Educação da Universidade do Oeste de Santa Catarina (UNOESC), Joaçaba/SC - Brasil. E-mail: cveruck2018@gmail.com

${ }^{3}$ Docente do curso de Especialização em Inovação na Educação da Universidade do Oeste de Santa Catarina (UNOESC), Joaçaba/SC - Brasil. E-mail: teixeira@upf.br 
diversified methodologies, allied to the use of technological means, in order to improve the pedagogical making of the student's reality and qualify it.

Keywords: Innovation; School education; Technologies; Active Methodologies.

\section{RESUMEN}

Las tecnologías digitales son herramientas que apuntan para la calificación de procesos educativos en la educación básica, pudiendo, incluso, permitir innovación en ese nivel de enseñanza. De esa manera, el presente trabajo de intervención pedagógica ocurrió con el objetivo de trabajar con los docentes la motivación y el cambio de visión en relación a la importancia del uso de las metodologías activas en el proceso educativo, por medio del uso de las tecnologías, despertándoles para la búsqueda del conocimiento y de la actualización profesional. Para atender ese intuito, se desarrolló un trabajo con base en las propuestas de metodologías activas, de manera remota, por medio del Google Meet, en la cual se realizó cuatro horas de un taller, dividido en dos momentos de dos horas cada, con una turma de 13 profesores actuantes en escuela de enseñanza fundamental de un municipio del interior de Santa Catarina (SC). En esos momentos se utilizó herramientas de modo que los docentes pudiesen participar activamente de todas las etapas de formación. Como resultados, se comprendió que la utilización de tecnologías en clase aún es observada como impedimento por varios docentes que participaron de la intervención. Sin embargo, se observó que eses aumentaron la percepción de la importancia de la introducción de metodologías diversificadas, aliadas a la utilización de medios tecnológicos, con el fin de perfeccionar el que hacer pedagógico de la realidad del alumno y calificarlo.

Palabras clave:

Palabras clave: Innovación; Educación escolar; Tecnologías; Metodologías activas.

\section{INTRODUÇÃO}

Na sociedade contemporânea, a educação vem passando por um processo de construção que permeia várias tendências e métodos de ensino, tendo como molde as conformidades impostas pela própria sociedade, esta que hoje se caracteriza por ser heterogênea, social, cultural e econômica, fazendo com que surja nas escolas a necessidade de adequação do contexto de sala de aula ao da vivência do dia a dia. Essa necessária adaptação envolve a adoção e uso (ou não) da internet, por meio de smartphones, tablets ou notebooks, e outros dispositivos móveis que captam sinais digitais, possibilitando amplo e maior acesso a serviços, pessoas e possibilidades. É cada vez maior e está cada vez mais disponível e necessária a conexão.

Em diversos ambientes - supermercados, shoppings, praças, reuniões, no próprio trabalho e também na escola - é possível visualizar diariamente pessoas conectadas à rede mundial de computadores, a internet, inclusive, na Escola $X$, na qual aconteceu a intervenção que aqui se apresenta, caracterizada como uma instituição escolar do campo, pois está localizada na zona rural. Nela a utilização da rede já se faz presente, sugerindo e justificando a mundialização da conexão.

O que motivou a opção por essa escola foi por conhecer sua realidade e sempre ter chamado a atenção o fato de esta ter somente um professor efetivo que, afastado em interstício aposentatório, caracteriza-a por $100 \%$ do corpo docente serem Contratados em Caráter Temporário (ACTs). Tal fato causa uma grande rotatividade de profissionais que se renovam a cada início de ano. Ademais, como resultado de ser uma escola em que os professores precisam dispor de transporte próprio, a opção por ela geralmente é descartada, talvez, por essa razão, permanecem os professores que apresentam menor habilitação, tempo de serviço e, consequentemente, menor experiência profissional, dentre outros aspectos. $\mathrm{O}$ acesso e a mobilidade, então, são fatores que influenciam na falta de estímulo 
para a adesão dos professores. Além dos pontos citados, destaca-se que a referida unidade é considerada uma escola do campo, fato que não desperta o interesse de muitos professores.

A inexperiência dos docentes, aqui constatada e relatada, fica nítida quando se observa a aplicação das aulas, com metodologias essencialmente tradicionais e sendo alvo constante de críticas por parte dos alunos e pais. Um dos aspectos percebidos, em direção à era "tecnológica" em que se está inserido, é o não uso dos recursos midiáticos com os alunos. Tal fato é comprovado por meio de registros em conversas via WhatsApp com a equipe gestora da Unidade Escolar. Assim, tem-se por hipótese que o processo de ensino-aprendizagem precisa ser qualificado e isso passa pela formação dos professores e pela ressignificação da importância do uso das tecnologias.

A partir do contexto exposto, ao se elaborar este projeto de intervenção, partiu-se do levantamento das carências da Unidade Escolar X, aplicando-se um questionário pela ferramenta Guia Eduteci para a gestora da instituição. Dessa forma, constatou-se a necessidade de o grupo de professores desmistificar o uso das tecnologias de aprendizagem e aplicá-las em sala de aula por meio das metodologias ativas.

Nessa perspectiva, objetivou-se trabalhar com os docentes a motivação e a mudança de visão em relação à importância do uso das metodologias ativas no processo educativo, por meio do uso das tecnologias, despertando-Ihes para a busca do conhecimento e da atualização profissional. Assim, o questionamento central desta pesquisa consistiu em identificar "Quais as possibilidades das metodologias ativas no processo de motivação dos docentes para o uso da tecnologia na educação em uma escola do campo?".

Salienta-se, nessa direção, que o intuito deste trabalho foi o de realizar uma intervenção baseada em metodologias ativas para a ampliação da percepção (visão) do potencial da informática para a educação, possibilitando que os professores participantes pudessem refletir e explorar tais recursos na formação docente e, em consequência, sentirem-se instrumentados a utilizá-los em sala de aula. Nesse sentido, estudou-se a receptividade dos professores à inovação pedagógica, entendida como as atitudes e novos papéis, mais ou menos favoráveis, que esses assumem diante de utilização de novos recursos tecnológicos.

Destaca-se aqui que se compreende a inovação na educação, dentre tantos outros aspectos, como sendo a utilização de metodologias claras, criadas a partir de pesquisa e ciência, que possam proporcionar aos alunos oportunidades para a construção de conhecimento e de vivências em todas as etapas de ensino. Sendo assim, a inovação em educação centra-se nas escolas, mais precisamente nas salas de aula e nas práticas dos professores, pressupondo a utilização de novos materiais ou tecnologias. Ainda, o uso de novas estratégias ou atividades e a alteração de crenças por parte dos participantes são componentes essenciais para que ocorra a inovação (FULLAN, 2007 apud OLIVEIRA; COURELA, 2013).

Frente ao exposto, este artigo apresenta a intervenção citada e organiza-se em cinco partes essenciais. A parte introdutória, que apresenta o tema, o problema e os objetivos da intervenção. Na sequência, o referencial teórico, que aborda as tecnologias educacionais em intrínseca relação com as metodologias ativas e a necessidade de inovação na educação. Em seguida, descreve-se a metodologia de trabalho e, na seção quatro, os resultados e discussões após a análise das produções e das falas dos professores nos dois momentos da aplicação. Por fim, as considerações finais. Importa destacar, conforme orientações do Decreto n. 562, de 17 de abril de 2020 (SANTA CATARINA, 2020), 
que em razão do momento vivenciado durante a execução do trabalho (distanciamento social em virtude da Pandemia Covid-19), a intervenção aconteceu de forma remota em dois dias, com duas horas de duração.

\section{REFERENCIAL TEÓRICO}

Para o desenvolvimento do presente trabalho adotou-se o embasamento da pedagogia históricocrítica (SAVIANI, 2005). Partiu-se, desse modo, por refletir a respeito do uso das tecnologias na educação e passou-se à análise delas para o uso das metodologias ativas, entendendo-se que seja um meio viável à promoção de uma educação de qualidade, tendo o estudante no centro do seu processo de construção histórica, social e cognitiva. A partir das leituras, reflexões e estudos, traçouse uma linha do tempo sobre que caminhos seguir, considerando as contribuições do discurso da inovação para a atuação docente.

Vive-se em um mundo em constante mudança, em uma sociedade regida por leis, valores e interesses mutáveis, que condicionam a forma de vida humana. Essa mutação de valores e interesses manifestase em transformações políticas, sociais, ideológicas, culturais e científicas. O sociólogo Bauman (2009), na perspectiva de trazer para as reflexões a transição entre a sociedade sólida e a líquida, verifica implicações desse processo transitório no contexto escolar. Assim, reconhece que, diante da sociedade líquida, o conhecimento é pouco valorizado e a esperança de melhores condições de vida por meio da educação está cada vez mais longe, o que, de certa forma, acaba distanciando os jovens da escola. Nesse mundo cheio de variáveis, vividas em condições de incerteza constante, a humanidade evolui e muda constantemente seus pensamentos quanto ao trabalho, à tecnologia, à escola e a todos os outros segmentos da sociedade.

Hoje, as inovações tecnológicas, os governos, a mídia e o mercado estão traduzindo um ambiente em que é cada vez mais fácil "apagar, desistir e substituir". $E$ a velocidade com que isso ocorre é que dá à vida esse caráter inconstante. É como se cada pessoa estivesse eternamente à procura de algo que possa ser seu novo objetivo ideal, conforme Bauman (2009), é próprio da era da sociedade líquida não existir a constância. O que dura é a impermanência, o neoliberalismo substitui o liberalismo, com mudanças no modo de organização da sociedade, que passa a ser centrada na lógica da competição. A globalização, com o neoliberalismo, provoca mudanças na força de trabalho com o capitalismo cognitivo e o modelo tecnicista. O ser humano de corpo dócil que era exigido até então, cede lugar ao uso do cérebro, da necessidade de pensar, planejar, executar e aprender.

Vale ressaltar que a modernidade líquida é o fenômeno que caracteriza o tempo atual, ela tem muito a oferecer de positivo, contanto que as pessoas estejam preparadas para fazerem a sua parte em relação ao desenvolvimento do mundo e de si próprios. Como diz Bauman (2009, p. 2): "No mutável mundo de hoje, [...] correr é melhor que caminhar." Ou seja, o indivíduo, como cidadão, em prol da sociedade e de si mesmo, não pode ficar parado, ou caminhar lentamente diante da evolução, precisa renovar-se, inovar. Diante dessa necessidade de evolução constante, pode-se visualizar que a educação vem passando por um processo de construção que permeia várias tendências e métodos de ensino. Isso, tendo como molde as conformidades impostas pela própria sociedade, fazendo com que surja nas escolas a necessidade de adequação do contexto de sala de aula ao da vivência do dia a dia. 
Nesse contexto, surgem, dentre outros, dois grandes desafios: a utilidade do conhecimento e a crise nos pressupostos pedagógicos, em que a construção do conhecimento acontece a partir do apelo à inovação. Sobremaneira, parece emergir a necessidade de mudanças na educação. Nesse sentido, há um crescimento do debate, nos últimos anos, em torno da inclusão de novas tecnologias na educação. Expressões historicamente configuradas, mudam de sentido com as alusões globalizantes e a figura do professor passa por um processo de mudança, tornando-se tutor, monitor, dentre outras denominações.

A escola desterritorializa-se, cedendo lugar às teleaulas ou aulas virtuais, síncronas, assíncronas, online e outros formatos, em que a presença física real não é mais (obrigatoriamente) necessária. 0 ensino passa a ser comercializado e/ou ministrado em pacotes, cursos, distâncias e formatos diversos. A partir de 1980, por influência da Organização das Nações Unidas para a Educação, a Ciência e a Cultura (Unesco), que já exercia influência nas políticas públicas, intensifica-se a disseminação da cultura digital. De acordo com Sampaio e Leite (2011), nos espaços escolares são introduzidas novas tecnologias/ferramentas e com elas a formação/capacitação dos professores, visando à alfabetização tecnológica para o trabalho com as mídias. No mesmo sentido, passam a coexistir políticas educacionais que visam à avaliação, bem como a busca por melhores resultados educacionais.

Desse modo, com a inserção da cultura digital pela influência de políticas, surge a visão determinista e, com ela, a necessidade de que as pessoas se adaptem, sem que haja um processo de inserção nelas. Contextualizar sua introdução se faz necessário no sentido de que a cultura digital é um modo de vida e as pessoas estão inseridas nela, pois somente a inserção de tecnologias não garante a qualidade no ensino, conforme afirma Garcia (2013). Nessa circunstância, a inovação na educação também pode ser compreendida ou questionada a partir de seu currículo, identificável, por exemplo, pelos Planos Políticos Pedagógicos (PPP) das escolas. Percebe-se a maioria deles padronizados a partir dos vários modos de gestão (democráticos ou não), de alta intensidade (processos democráticos) ou baixa intensidade (um documento normativo). Esses PPP, atrelados ao discurso da inovação, podem vir a ser regulatórios (a inovação é imposta) ou emancipatórios (ação-reflexãoação, em que a inovação é vista como um processo).

Em relação às práticas pedagógicas, não cabe somente classificá-las como boas ou más, pois se vive em uma sociedade em constante mudança e se deve compreender o processo em que acontecem os fatos, bem como contextualizá-los, no sentido de entendê-los. A escola é colocada como culpada pelos problemas da sociedade, que a estrutura não serve para a atualidade. Mas essa mesma escola sempre é convocada para as mudanças na sociedade, bem como os seus professores, constantemente chamados à inovação, entendida como uma ruptura paradigmática. Assim, os docentes devem proporcionar uma reconfiguração de saberes a fim de favorecer o trabalho no sentido de transformação. A inovação deve ser tratada em uma dimensão emancipatória, não como negação da história, mas no sentido de que a partir dela se possa avançar o processo de mudança, imposta pela lógica da competição (FORSTER; FAGUNDES, 2006).

Esse novo mundo exige de cada professor uma nova maneira de pensar e agir. Esses profissionais precisam ter uma pedagogia voltada à nova era, a era tecnológica. Entende-se que, no mundo atual, é dever do governo junto às escolas criar uma pedagogia que possa atender às novas necessidades de produção e às contemporâneas culturas digitais que estão se desenvolvendo. De acordo com Tedesco (2004), a escola precisa mostrar para os alunos e demais pessoas como agir e viver em meio 
à essa explosão tecnológica de que estão rodeados, uma vez que os indivíduos precisam aprender a usufruir de todos os benefícios que a tecnologia traz.

Assim, as tecnologias e os meios de comunicação em massa podem oferecer muito aos professores e alunos. Seu maior benefício é o de diminuir as distâncias nas pesquisas, na busca pela informação, por exemplo, permitindo a navegação pelas bibliotecas virtuais, nas quais se pode usufruir de diversos tipos de livros sem a necessidade de sair de casa. Outra ilustração são as plataformas de ensinoaprendizagem, de onde é possível a modalidade de ensino a distância e ensino remoto, como ocorre na rede estadual de ensino de Santa Catarina (SC), permitindo um contato constante com professores em um ambiente virtual. É maravilhoso como as tecnologias ao longo do tempo estão se aprimorando mais e contribuindo para uma educação melhor. Com isso, tanto o aluno quanto o professor ganham importantes papéis na sociedade tecnológica. Aqueles devem saber como usar toda essa informação e separar o inútil do útil, esses devem também saber utilizar todas essas ferramentas, de modo que isso possa contribuir dentro da sala de aula para a efetivação de uma educação de qualidade.

Diante dessas necessidades, evoluções, evidências e tendências, pode-se entender essas vivências no cenário de informação e comunicação em que a escola e a educação formal estão inseridas. Segundo Lévy (1999, p. 17), por meio de dois conceitos relacionados entre si, cibercultura e ciberespaço:

O termo [ciberespaço] específica não apenas a infraestrutura material da comunicação digital, mas também o universo oceânico de informação que ela abriga, assim como os seres humanos que navegam e alimentam esse universo. Quanto ao neologismo "cibercultura", especifica aqui o conjunto de técnicas (materiais e intelectuais), de práticas, de atitudes, de modos de pensamento e de valores que se desenvolvem juntamente com o crescimento do ciberespaço.

A partir de tais conceitos se busca entender o que seria inovação na educação, bem como sua aplicabilidade na docência. Segundo Nóvoa (1988, p. 8),

a inovação não se decreta. A inovação não é um produto. É um processo. Uma atitude. É uma maneira de ser e estar na educação que necessita de tempo, uma ação persistente e motivadora, requer esforço de reflexão e avaliação permanente, por parte dos diversos intervenientes do processo inovador.

Para suprir necessidades criadas pelos desafios, a inovação em sala de aula surge como "norte", pois segundo Carbonell (2002, p. 20),

existe uma definição bastante aceitável que define a inovação como um conjunto de intervenções, decisões e processos, com certo grau de intencionalidade e sistematização, que tratam de modificar atitudes, ideias, culturas, conteúdos, modelos e práticas pedagógicas.

Ao compreender esse conceito de inovação, entende-se que as tecnologias em sala de aula, por si só, não produzirão os avanços tão necessários à educação. É necessário metodologias para utilizar, da melhor forma, tais ferramentas. Sendo assim, o uso das metodologias ativas parece despontar como fundamental para formar sujeitos mais ativos, reflexivos e críticos, que ultrapassem os limites puramente teóricos e/ou técnicos. Tal metodologia é um caminho possível para formar alunos que tomem parte do processo de sua formação, ampliando, dessa forma, o seu olhar a respeito dos diversos contextos em que se insere. Cabe aqui salientar que metodologias ativas são estratégias de ensino centradas na participação efetiva dos estudantes na construção do processo de aprendizagem, de forma flexível, interligada, híbrida. 
As metodologias ativas em um mundo conectado e digital se expressam por intermédio de modelos de ensino híbridos, com muitas possíveis combinações (MORAN, 2017). Ainda de acordo com Berbel (2012), entre os objetivos das metodologias ativas citam-se o incentivo e a motivação do sujeito aprendente pela busca por novos conhecimentos, ao mesmo tempo que insere a teoria e estimula a busca por elementos ainda desconhecidos.

Quando acontece a aprendizagem com metodologias ativas, o papel protagonista do estudante ganha ênfase, pois esse se envolve diretamente, participando e refletindo em todas as etapas do processo. É a ele concedido, enquanto aluno, a experiência de ir experimentando, desenhando, criando, com orientação do professor. No entanto, isso exige uma mudança de configuração do currículo, da participação dos professores, da organização das atividades didáticas, da organização dos espaços e tempos. Além disso, ocorre a urgência na mudança de mentalidade da equipe gestora, para que perceba a necessidade e importância da utilização de métodos e ferramentas diferenciadas a fim de que o processo de ensino-aprendizagem se concretize de forma eficaz (BACICH; TANZI NETO; TREVISANI, 2015).

Para José Moran (2014), são muitos os benefícios ao se trazer as metodologias ativas para dentro da sala de aula, uma vez que elas precisam acompanhar os objetivos pretendidos. Objetivando alunos proativos, há a necessidade de utilizar metodologias que os envolvam em atividades cada vez mais complexas, em que tenham que tomar decisões e avaliar os resultados, com apoio de materiais relevantes. E para que sejam criativos, eles precisam experimentar possibilidades diversas de mostrar sua iniciativa. A proposta das metodologias ativas é que o estudante esteja no centro do processo de aprendizagem, participando ativamente e sendo responsável pela construção de conhecimento.

Na discussão acerca da metodologia ativa em um contexto de mudanças de paradigmas nos papéis do professor e do aluno, esse não é mais o único responsável por conduzir o ensino, mas passa a ser orientador do processo, enquanto o aluno assume o papel de protagonista de sua aprendizagem. Portanto, alguns exemplos de metodologias ativas são: a sala de aula invertida, o ensino híbrido, a gamificação, a rotação por estações. Esses se constituem em alguns métodos de ensino que facilitam as diretrizes propostas pela Base Nacional Comum Curricular (BNCC), de modo a guiar o professor na inclusão e utilização da tecnologia como ferramenta pedagógica. Ademais, encaminham para processos de inovação na educação (VIEGAS, 2019).

Dentre as propostas, como visto, das metodologias ativas, está a sala de aula invertida. Nesse sentido, Moran (2014, p. 22-23) afirma que:

um dos modelos mais interessantes de ensinar hoje é o de concentrar no ambiente virtual o que é informação básica e deixar para a sala de aula as atividades mais criativas e supervisionadas. É o que se chama de aula invertida. A combinação de aprendizagem por desafios, problemas reais, jogos, com a aula invertida é muito importante para que os alunos aprendam fazendo, aprendam juntos e aprendam também, no seu próprio ritmo. Os jogos e as aulas roteirizadas com a linguagem de jogos cada vez mais presentes no cotidiano escolar. Para gerações acostumadas a jogar, a de desafios, recompensas, de competição e cooperação é atraente e fácil de perceber.

Muito em voga no momento atual (Pandemia Covid-19), está o termo ensino híbrido. Este, diante de inúmeras outras definições, pressupõe a mistura, a hibridização, a junção de metodologias ativas com modelos flexíveis que tragam contribuições importantes para o desenho de soluções atuais aos aprendizes de hoje. Para Coll (2000), o aprendizado, no modelo híbrido, acontecerá a partir de 
problemas e situações reais, os mesmos que os alunos vivenciarão depois na vida profissional. Esse direcionamento contribui para que o estudante seja corresponsável por seu próprio processo de formação e autor da sua aprendizagem, a partir do momento em que participa de atividades, como leitura, escrita, discussão ou resolução de problemas. Ainda, quando promove e atua em atividades de síntese, análise e avaliação do conteúdo. A aprendizagem híbrida destaca a flexibilidade, a mistura e o compartilhamento de espaços, tempos, atividades, materiais, técnicas e tecnologias que compõem esse processo ativo (MORAN, 2017).

Observa-se, assim, que a educação contemporânea parece direcionar-se à efetividade das metodologias ativas e à necessária concretização do ensino híbrido. Mais do que isso, tais tendências somente se operacionalizarão com a presença das tecnologias dentro da escola, da sala de aula. Nessa lógica, o documento norteador da educação básica, a BNCC, prevê o uso de tecnologias em sala de aula com o objetivo de que os alunos a utilizem de maneira crítica e responsável ao longo de sua formação escolar. A normativa é clara, quando afirma o papel fundamental da tecnologia no processo de ensino-aprendizagem como um dos pilares da chamada cultura digital. Pode-se dizer que na BNCC existem duas, das dez competências gerais, que estão relacionadas à tecnologia, a quarta e a quinta (são as competências tecnológicas):

40: Utilizar diferentes linguagens - verbal (oral ou visual-motora, como Libras, e escrita), corporal, visual, sonora e digital -, bem como conhecimentos das linguagens artística, matemática e científica, para se expressar e partilhar informações, experiências, ideias e sentimentos em diferentes contextos e produzir sentidos que levem ao entendimento mútuo.

50: Compreender, utilizar e criar tecnologias digitais de informação e comunicação de forma crítica, significativa, reflexiva e ética nas diversas práticas sociais (incluindo as escolares) para se comunicar, acessar e disseminar informações, produzir conhecimentos, resolver problemas e exercer protagonismo e autoria na vida pessoal e coletiva. (BRASIL, 2018, p. 11).

Recobrando-se o exposto sobre as metodologias ativas e as tecnologias, retoma-se um dos pilares essenciais deste trabalho, a inovação. Assim, compreende-se que, por meio das metodologias ativas, as ferramentas pedagógicas que possibilitam inovar são as tecnologias de comunicação e informação (TIC). Ainda, o uso de dispositivos, como tablets, smartphones e computadores, como aliados para facilitar o trabalho, não como quesito obrigatório para que a inovação aconteça, mas como ferramenta para um processo crítico, reflexivo e cultural e historicamente situado. Para tanto, é imprescindível ao professor rever conceitos e papéis no processo de aprendizagem (educador e aluno). Se assim o é, torna-se fundamental o processo de formação, seja ela inicial ou continuada.

\section{METODOLOGIA}

A intervenção pedagógica realizada, metodologicamente, ganha contornos de uma pesquisa qualitativa e quantitativa (quanto à forma de abordagem do problema) e, em razão do método de estudo, de uma pesquisa-ação. De acordo com Thiollent (2011, p. 24),

podemos considerar que, internamente ao processo de pesquisa-ação, encontramos qualidades que não estão presentes nos processos convencionais. Por exemplo, podemos captar informações geradas pela mobilização coletiva em torno de ações concretas que não seriam alcançáveis nas circunstâncias da observação passiva. Quando as pessoas estão fazendo alguma coisa relacionada com a solução de um problema seu, há condição de estudar este problema num nível mais profundo e 
realista do que no nível opinativo ou representativo no qual se reproduzem apenas imagens individuais e estereotipadas.

Sendo assim, faz-se necessário enfatizar que a pesquisa-ação é uma metodologia da pesquisa social, com uma linha orientada para a resolução de problemas com objetivos de transformação. Nesse processo, a participação de todos os envolvidos no estabelecimento de ensino é incentivada, visando à procura de soluções para suas próprias defasagens detectadas por intermédio de pesquisa. Os objetivos teóricos são a todo momento retomados e reafirmados com situações em que ocorre o diálogo aberto em linguagem comum a todos (THIOLLENT, 2011).

A partir de tais pressupostos, o trabalho de intervenção foi realizado na Escola $X$ (nome fictício adotado para preservar a identidade desta), localizada em uma comunidade distante 13 quilômetros do centro da cidade do interior de um município (com 74.641 habitantes) do estado de SC. A referida Unidade Escolar atende 140 estudantes da educação básica, divididos em nove turmas de primeiro a nono ano do ensino fundamental (Figuras 1 e 2). É considerada uma escola do campo e, conforme afirma Cordão (2010), por assim ser, é necessário reconhecer as suas peculiaridades, como tempo, saberes, identidade e memória coletiva. A partir delas se redireciona o olhar à cultura, aos sonhos e às necessidades dos que ali vivem, por meio da efetivação e democratização das políticas públicas para essa modalidade educativa.

Figura 1 - Entrada da Escola X

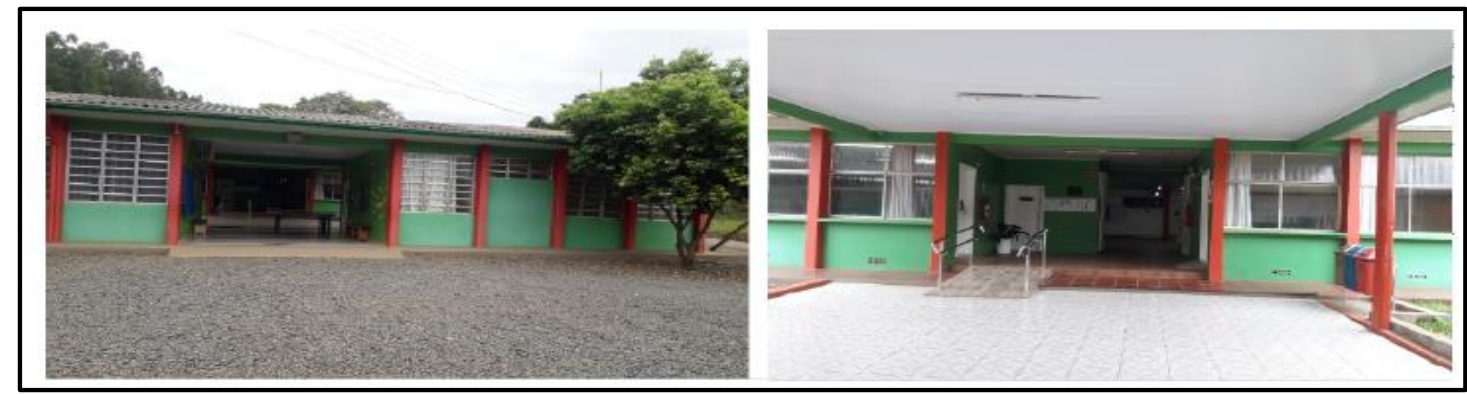

Fonte: Acervo da instituição (2020).

Figura 2 - Área externa da Escola X

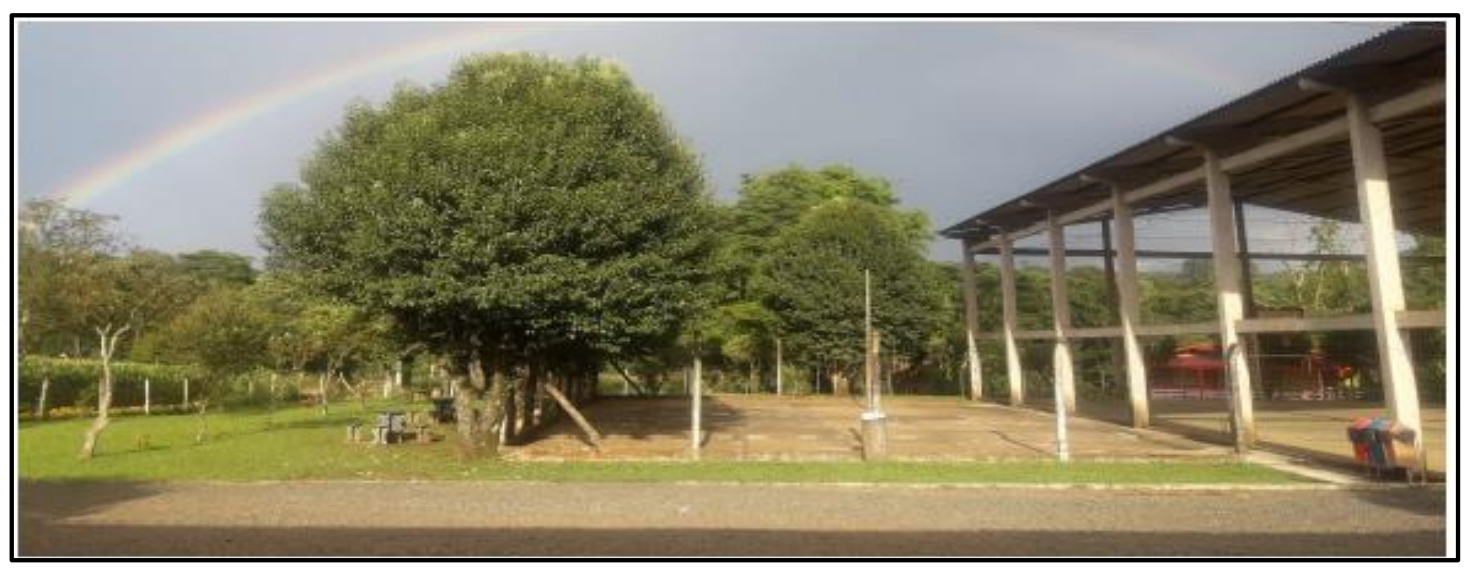

Fonte: Acervo da instituição (2020).

São 15 professores que atuam no educandário e, como já afirmado anteriormente, todos ACTs. A Unidade Escolar conta ainda com uma gestora e uma assistente de educação que realizam o trabalho pedagógico e o administrativo. Na escola há rede de internet com Wi-fi disponibilizada para utilização dos professores e no laboratório de informática, que está equipado com 10 computadores, além de dois projetores de multimídia que podem ser utilizados na sala de aula e usados como lousa digital. 
Assim, a amostra de pesquisa conformou-se por um grupo de 13 professores da Escola X: um professor de Matemática, um professor de Língua Portuguesa, um professor de Educação Física, um professor de Geografia, dois professores de Arte (sendo uma a gestora), seis pedagogos com atuação nas séries iniciais e segundo professor nas séries finais e uma pedagoga que atua como Assistente de Educação. Para preservar a identidade dos sujeitos, estes serão denominados neste artigo por letras ( $\mathrm{A}$ a N), conforme Quadro 1:

Quadro 1 - Caracterização da amostra de pesquisa

\begin{tabular}{|c|c|c|c|}
\hline Professor & Disciplina que atua & Tempo de atuação & Formação \\
\hline A & Arte & 4 anos & Graduado na área \\
\hline B & Pedagogia & 4 anos & Especialização na área \\
\hline D & Pedagogia & 6 anos & Especialização na área \\
\hline E & Pedagogia & Menos de 1 ano & Graduado na área \\
\hline F & Pedagogiaii & 20 anos & Atuando como gestora \\
\hline G & Geografia & 7 anos & Graduado na área \\
\hline H & Língua Portuguesa & menos de 1 ano & Graduado na área \\
\hline I & Pedagogia & 3 anos & Graduado na área \\
\hline J & Matemática & 3 anos & Graduado na área \\
\hline L & Pedagogia & 3 anos & Graduado na área \\
\hline M & Educação Física & 2 anos & Graduado na área \\
\hline Pedagogia & de educação \\
\hline
\end{tabular}

Fonte: os autores.

Salientamos que a intervenção aconteceu de forma remota por meio do Google Meet, em dois momentos com duas horas de duração cada um, sendo que previamente foi realizado questionário para diagnóstico a fim de sabermos quais as defasagens do grupo de professores, em relação à importância do uso das metodologias ativas no processo educativo, por meio do uso das tecnologias.

\section{APLICAÇÃo E ANÁLISE DA INTERVENÇÃo}

Como justificativa da mundialização, mesmo o espaço de intervenção sendo uma escola localizada na zona rural, a utilização da rede já se faz presente por meio da posse de dispositivos móveis, com acesso à internet por parte dos estudantes. Percebe-se essa realidade também a partir do questionário aplicado aos professores, no qual fica comprovado que $100 \%$ deles têm acesso à 
internet. Ou seja, embora conectados, deparam-se com desafios por não conseguir ter domínio das TIC para dar conta da aprendizagem de seus alunos.

Quando questionados sobre o uso de tecnologias em sala de aula e quais utilizam como recurso, obteve-se algumas respostas como por exemplo, o professor G diz que utiliza "sala de informática, data show, vídeos." O professor M manifesta que utiliza "Google sala de aula, formulários, vídeos explicativos para facilitar o processo. Ainda não tive coragem de gravar um Meet." O professor C infere que "às vezes sim, uso de celular e computadores para pesquisas." No entanto, o professor B responde que "poucas, devido à realidade e condições dos alunos." Ainda, constatou-se que a totalidade dos profissionais da Unidade Escolar possuem aparelho celular, porém poucos o utilizam como ferramenta pedagógica. O mesmo acontece com a posse de notebook com webcam, que somente um professor não possui (tem computador) e, mesmo assim, ocorre pouca utilização do meio tecnológico em sala de aula para o fazer pedagógico.

Em relação à formação e experiência profissional, 53,8\% do corpo docente da Unidade Escolar atuam de um a cinco anos na educação, ficando nítida a falta de experiência, quando esse dado é complementado com $15,4 \%$ que têm menos de um ano de experiência. Quanto à formação, $61,5 \%$ têm formação na área que atuam e 30,8\% possuem especialização. Também chamou atenção no questionário de inscrição os $23,1 \%$ de respondentes que disseram não ter participado de nenhuma formação sobre metodologias ativas e, mesmo assim, quando perguntados se se consideram como professores inovadores, $92,3 \%$ admitiram que sim. Diante disso, surge o questionamento: desconhecem as metodologias ativas ou as usam sem saber o que são? Nessa direção, ao se analisar as respostas para a pergunta "O que entendem por metodologias ativas?", deparou-se com professores respondendo que "não sabem nada". Cabe lembrar que são professores da rede estadual de ensino e que está, após o fechamento das escolas em consequência do início da Pandemia Covid19 (março/2020), proporcionou várias formações, tratando inclusive das metodologias ativas para trabalhar durante o período de ensino remoto.

No primeiro momento que trabalhou-se a produção da nuvem de palavras com os professores, 0 tema "tecnologia x práticas pedagógicas", percebeu-se que o termo que mais se destacou foi "conhecimento". Na sequência, evidencia-se a palavra desafio.

\section{Defina em uma palavra: Tecnologia $X$ Práticas Pedagógicas.}

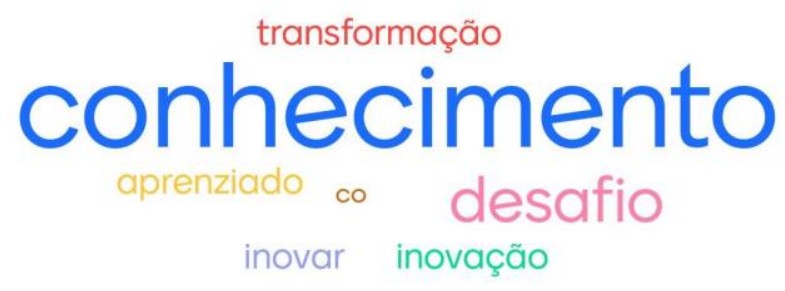

Fonte: autores 
Analisa-se que a maioria percebe que utilizando tecnologias aliadas às práticas pedagógicas é possível facilitar a aquisição do conhecimento. No entanto, há quem considere um desafio, cabendo aqui se questionar o sentido em que este "desafio" foi pensado: desconhecem ou não utilizam em razão de dificuldades.

Na produção do mapa mental foi nítido o espírito de liderança e inovação de alguns professores, que se apressaram em fazer a leitura e explorar a ferramenta sugerida. Percebe-se o entrosamento de alguns, bem como a colaboração na produção coletiva, pois somente um trabalho seria socializado com os participantes da oficina. Ficou evidente, também, os que se escondem por trás da câmera desligada para deixar os demais realizarem o trabalho que seria do grupo. Saíram boas análises das leituras e os que leram realmente fizeram ótimos apontamentos para a produção final e todos terminaram o dia e o primeiro momento com a noção de qual é o lugar das pedagogias inovadoras. A partir da visão de Carbonell (2002) e da fala durante a exposição do mapa mental do Grupo 1, destaca-se:

Colocamos o título do Mapa Pedagogias Inovadoras? só que com um ponto de interrogação. A gente falou lá na outra conversa que às vezes a gente acha que está inovando com aquela forma, com aquele método, mas na verdade a gente está fazendo um método tradicional mascarado, então cabe a pergunta: será que realmente são inovadoras? Inclusive no texto tem críticos que dizem que acreditam no fim das pedagogias inovadoras [...] falam sobre o óbito destas tendências. [...] existem várias escolas que foram centradas em pedagogias libertadoras que deram certo e que dão certo. [...] Outro tópico que a gente fala é sobre o ativismo que é a atividade pela atividade ou o jogo pelo jogo que às vezes a gente ouve falar. $\mathrm{O}$ que significa que esse ativismo a gente vai lá e faz tipo uma gincana dentro da sala de aula, com muita atividade física e pouco conteúdo e pouca reflexão de fato [...] o professor acaba esquecendo de mediar essa atividade [...] (Professor J).

A relação das três visões de ser professor na era digital - o cético, o otimista e o pessimista - a partir da leitura de Pozo e Aldama (2014), ficou explícita na fala do Professor C, ao afirmar que

[...] os otimistas acreditam que as tecnologias de comunicação são atrativas porque oportunizam criação, comunicação multimídia [...] tem a questão dos jogos de simulação de jogos de interação então ela se torna mais atrativa. Aí nós temos os pessimistas que são aqueles que acreditam que não surte efeito, que não seja atrativo porque tem a questão do imediatismo que é tudo muito de repente muito rápido muito para agora né. A questão da gestão então que se depender só do aluno, então fica comprometida. Tem sempre a necessidade de mediação, tem que ter apresentação do professor né, porque o computador não vai ensinar tudo, tem coisas que precisa do professor para auxiliar mesmo tendo essa questão do computador torna, acaba causando um certo empobrecimento cognitivo nos alunos e até que essa questão da autoridade do ensino então que também fica comprometido. E tem também os incrédulos que eles são céticos [...] eles acreditam que não é bom não é ruim porque não tem mudança, aí entra naquela questão que os alunos eles não sabem buscar informação, que eles vão sozinhos aí então não sabem traduzir códigos [...] apesar de muita informação ao mesmo tempo existe também aquela questão de que elas às vezes são contraditórias [...] aluno que ele foi fazer uma pesquisa ele não vai ter ele não vai buscar mais do que uma fonte quando ele buscar mais do que uma fonte às vezes as informações elas vão ser contraditórias aí entra a questão das fake news $[\ldots]$.

Nesse ponto, após as explanações dos dois grupos, retomou-se a nuvem de palavras e solicitou-se que fizessem um comparativo entre os dois momentos e comentassem se alterariam a palavra que puseram para a formação da nuvem. Todos os professores afirmaram que não mudariam, uma vez que todas as palavras postas vieram ao encontro do conteúdo dos textos lidos, bem como dos mapas 
produzidos. A partir desse momento, alguns professores se perceberam como inovadores e isso foi observado quando realizaram a atividade "Eu Inovador" (seguindo o roteiro: O que? Como? Avaliação do produto final) e descreveram atividades que realizavam no dia a dia, utilizando as mais variadas metodologias.

No segundo dia da intervenção realizou-se o quiz do Kahoot, a maioria dos professores afirmou ter lido os dois textos que haviam sido disponibilizados via Google Drive e isso ficou perceptível quando respondiam aos questionamentos com poucos ou nenhum erro. Analisou-se, com eles, após a aplicação, o quanto os seres humanos são competitivos e como é possível usar esta condição para o ensino, utilizando, assim, a aprendizagem por meio dos jogos. Ao término da atividade, obteve-se um diagnóstico sobre quais os pontos do conteúdo que os alunos não haviam assimilado. Percebeuse que essas estratégias podem motivar pessoas e até influenciá-las psicologicamente, pois os jogos são dinamizados em objetivos e metas, com obstáculos a serem superados a fim de atingir a vitória.

Por meio dessa teoria, é possível traçar o paralelo entre um jogador e o aluno, que também supera obstáculos/problematizações para atingir metas e objetivos, aumentando a sua participação e extraindo os elementos agradáveis e divertidos dos jogos para aprender. Entretanto, é preciso estar atentos para o fato de que apenas dar pontos para a entrega de tarefas ou atividades não caracteriza gamificação, mas sim somente a utilização de mecânicas dos jogos. De acordo com Tolomei (2017, p. 149), "atividades divertidas e gamificadas podem engajar públicos diferentes e com idades diversas. E o engajamento está diretamente ligado à relevância dos conteúdos, às pessoas e à forma como a aprendizagem é motivada."

Segundo Martins et al. (2014), os jogos apresentam características que auxiliam no desenvolvimento de habilidades dos jogadores em um nível mais profundo. Para esses autores, alguns dos princípios de aprendizagem que os jogos desenvolvem são a construção de uma identidade, o comprometimento, a interação, a produção, o assumir riscos e desafios. Para os referidos autores, a partir do mundo virtual, há o comprometimento dos jogadores com a interação. Ainda, os "jogadores" precisam tomar decisões e agir e o jogo, conforme as atitudes do jogador, oferece feedbacks e novos problemas. Em jogos on-line, os jogadores interagem entre si, planejando ações e estratégias, entre outras habilidades. Ademais, nos jogos, os alunos produzem ações e redesenham as histórias, individualmente ou em grupo. Também correm riscos, experimentam, exploram - se erram podem voltar atrás e tentar novamente até acertar. Importante e positivo destacar que os jogadores estão sempre enfrentando novos problemas e precisam estar prontos para desenvolver soluções que os elevem de nível nos jogos. Portanto, os jogos estimulam o desafio por meio de problematizações que "empurram" o jogador a aplicar o conhecimento atingido anteriormente. Para Santos (2016),

Além de ser uma ótima maneira de envolver e se concentrar uma sala de aula, os quizzes podem ser utilizados para avaliar formativamente o conhecimento de cada indivíduo na sala. Eles podem ser usados para acompanhar o progresso dos estudantes ao longo do processo de ensino e aprendizagem.

Nessa perspectiva, a gamificação e a utilização de jogos entra como atividade social. Por isso, nada mais certo que faça parte também de cenários educativos, proporcionando ao estudante a vivência de experiências de aprendizagem que talvez não fosse tão fácil de ser alcançada por meio do ensino tradicional, como afirma Tolomei (2017). Desse modo, a gamificação aplicada como estratégia de ensino à geração que conhece e entende os conceitos dos games apresenta resultados positivos no engajamento, motivação e cooperação. 
Para complementar a aplicação do quiz foi exibido o vídeo "Tecnologia ou Metodologia", que aborda uma sala de aula onde foi introduzida a tecnologia, no entanto, as metodologias da professora continuaram as mesmas. Positivamente, essa foi a constatação de todos na roda de conversa realizada posteriormente ao vídeo. O professor $\mathrm{J}$ argumentou e os professores $\mathrm{E}, \mathrm{C}$ e $\mathrm{D}$ complementaram:

Eu já vi muito isso acontecer, e às vezes até nas nossas aulas a gente acha que está inovando, utilizando uma metodologia legal assim, mas no fim não muda nada e às vezes a gente sem querer mesmo acaba cometendo esse erro né! (Professor J).

O espaço de tempo que ela teve para aprender, aprender rápido. Uma semana ela já estava inovando né, que eu acho que impossível né. Um exemplo foi nós esse ano né, em função da... a gente era acostumado lá na escola, na sala de aula com quadro branco e daí tu vê que tu tem que mudar tudo, né. Começar a aprender tudo de novo [...] e ela na verdade continuou na mesmice né, porque só o que mudou foi a lousa e o projetor (Professor E).

[...] a gente estava na nossa zona de conforto da sala de aula e em questão de uma semana a gente teve que correr atrás e aprender a nadar. $E$ eu lembrei também de uma situação, há uns dois anos atrás, porque o que me chamou atenção neste vídeo é que cada aluno tinha o seu computador, né, [...] e que não é só o professor que tem que aprender [...] a gente vê pelos alunos: todos têm redes sociais, todos sabem o que está "rolando na rede" é o papo deles, mas quando você leva pra sala de informática eles não sabem nem utilizar um Word para digitar um texto [...] (Professor C).

Os alunos precisam treinar isso, e às vezes nem nós professores tivemos um treinamento. Eles chegam, colocam as ferramentas, tecnologias novas e nem nós sabemos usar tais tecnologias e não fornecem cursos pra gente e se a gente quiser, claro que nós temos que estar em constante inovação e ir atrás disso [...] (Professor D).

Reafirmando as exposições, as interventoras expuseram que os profissionais da educação devem inovar com a utilização das ferramentas tecnológicas, acompanhando as novas tendências educacionais. No entanto, não esquecendo que a máquina por si só não funciona sem comando, que não basta apenas possuir equipamentos ultramodernos se o professor não souber utilizá-lo de maneira que o aluno possa interagir em sala de aula. Ou seja, a tecnologia somente é válida se usada como meio de transformar a informação em conhecimento.

Continuando a reflexão, salientou-se que não adianta mudar as ferramentas tecnológicas e ainda usar a mesma metodologia, é necessário, por parte do professor, haver estudo, método e planejamento para que a tecnologia exerça seu papel de aliada educacional. No momento atual, com essa pandemia, tempos de muita mudança, entrou-se em um processo de reaprender o aprender, pois às vezes é preciso se despir de um aprendizado para vestir outro. O fato é que está claro que os professores têm o papel de mediadores, facilitadores ou, ainda, ativadores do conhecimento e o aluno é o centro do ensino e da aprendizagem, com base nos princípios que constituem as metodologias ativas.

Como forma de sistematizar o conhecimento adquirido, disponibilizou-se o link de um documento criado previamente no Google Docs, no qual constava uma tabela criada com os nomes dos participantes. A solicitação foi de que todos deveriam acessar esse documento e produzir um parágrafo respondendo ao questionamento: Como desmistificar o uso das tecnologias na educação, a partir das leituras e reflexões realizadas? Percebe-se que ninguém teve dificuldade na realização da 
atividade, pois todos, imediatamente após a solicitação, acessaram o documento e começaram a produzir. Em sequência, esse parágrafo produzido deveria (nos grupos formados no primeiro dia da intervenção) ser transformado em um vídeo para ser socializado com todos. Deixou-se livre a ferramenta para a produção e sugeriu-se que utilizassem a que melhor se adaptassem. Na realização desta atividade a principal dificuldade visualizada foi com a utilização de ferramenta para produzir o vídeo, pois o simples ato de gravá-lo com o próprio celular era desconhecido por alguns. Mas a atividade foi realizada e o vídeo exposto ao grupo. Novamente a liderança de alguns se destacou, pois já sugeriram ferramentas e começaram a produção do trabalho solicitado.

Nesse sentido, Moran (2014) afirma que se vive em um momento diferenciado do ponto de vista do ensinar e aprender. Aprende-se de várias maneiras, em redes, sozinhos, por intercâmbios, em grupos, dentre outras. Para o autor, essa liberdade de tempo e de espaço configura um cenário educacional novo, em que várias situações de aprendizagem são possíveis com a ajuda das chamadas metodologias ativas. Ele acrescenta que o papel do professor é alterado, passando daquele que ensina para aquele que faz aprender e que também aprende, criando um ambiente capaz de tornar o aluno motivado.

No decorrer da intervenção, o único empecilho foi o tempo, pois apesar de ter sido cronometrado, programado com antecedência e deixado sempre uma margem de segurança entre uma atividade e outra, ele mostrou-se escasso. Nos dois momentos foi ultrapassado o tempo programado, em razão de que as discussões sempre aconteceram após a realização de cada momento. Não houve reclamações dos participantes em relação a isso, porém foi um fato constatado pelos autores.

Quanto a ter havido obstáculos no desenvolvimento e execução do projeto, destaca-se que, considerando que a intervenção não foi presencial, conforme o Decreto n. 562, de 17 de abril de 2020, que trata sobre o distanciamento social, não se percebeu dificuldades na aplicação da intervenção. Houve um público maior do que o esperado, em consequência das dificuldades que todas as escolas enfrentam em relação às reuniões e formações on-line, pelo momento que os professores estão vivenciando de muito trabalho administrativo e pedagógico. Das 13 inscrições, somente uma, no segundo dia, não aderiu à oficina. Referente à receptividade e envolvimento dos participantes em relação às atividades desenvolvidas, os autores afirmam que foram acolhidos pelo grupo, houve a participação da gestora e da assistente de educação. Em relação à participação do grupo, alguns professores destacaram-se mais, outros menos nos momentos de discussão, porém, sempre o grupo ficou bem à vontade, não sendo pressionado a falar. Identificou-se um resultado positivo na realização das atividades, pois todos realizaram com responsabilidade e atenção.

Para que os autores tivessem uma noção da validade ou não da aplicação da intervenção, disponibilizou-se aos participantes o link http://gg.gg/avalia ao final, para que realizassem a avaliação da atividade. Havia quatro questões abertas, que objetivavam perceber pontos positivos e negativos da intervenção, sugestões do que poderia ter sido feito diferente, bem como o que haviam assimilado das atividades realizadas e dos textos lidos. Quanto ao resultado, afirma-se que tiveram a oportunidade de participar de um curso onde puderam aprender fazendo, conforme escrita do Professor J:

[...] passar esse tempo em formação, foi de grande valia e muito conhecimento. Sobre as tecnologias temos muito a aprender, pois nos desafia muito. As tecnologias aplicadas por vocês todas foram muito importantes e não as conhecia. 
Em relação ao que assimilaram da oficina, destacaram que a visão da utilização e a importância da tecnologia em sala de aula mudou. Conforme afirmações dos professores J e C:

Fez-me refletir sobre meu papel na sala de aula e sobre como deixo meu aluno como "centro" do processo. Fez eu pensar também em metodologias diferentes que, aliadas às tecnologias, influenciarão positivamente o aprender. (Professor J).

Com certeza, temos que repensar nosso planejamento e o objetivo da nossa aula a todo momento, rever e compreender a realidade do nosso aluno e as mudanças/ avanços tecnológicos em todo momento. (Professor C).

Percebe-se nessas falas que os professores conseguiram perceber a necessidade de aliar tecnologia com metodologia diferenciada.

\section{CONSIDERAÇÕES FINAIS}

Entende-se que as metodologias ativas são estratégias de ensino centradas na participação efetiva dos estudantes no processo de construção do processo de aprendizagem, de forma reflexiva, interligada, híbrida. As metodologias ativas em um mundo conectado e digital se expressam mediante ensinos híbridos. Assim, ao término da intervenção percebe-se que os docentes participantes estavam carentes de conhecimento relacionado à utilização de tecnologias aplicadas na prática, bem como do conceito de metodologias ativas, pois alguns já faziam delas sem se dar conta do que se tratava.

Em um contexto social cada vez mais digital e globalizado, exige-se uma educação cada vez mais inclusiva, ainda, que contemple a diversidade humana e seja capaz de desenvolver habilidades indispensáveis para o exercício da plena cidadania, o que inclui o direito ao acesso às tecnologias, para que os estudantes possam aproveitar tudo o que elas podem proporcionar. Nessa direção, em relação à utilização de metodologias, percebe-se a importância de se combinar aprendizagem ativa e híbrida com tecnologias móveis, pois essa interlocução torna-se poderosa para desenhar formas interessantes de ensinar e aprender.

Para que a prática inclusiva aconteça, é necessário que as instituições se adaptem a fim de promover o desenvolvimento dos alunos, e não o contrário, tendo em vista que estes aprendem de formas diferentes e que cada um tem o seu próprio ritmo e tempo de aprendizagem, formando o pensamento investigativo e crítico perante alguma situação. Desse modo, em virtude dos fatos mencionados, acredita-se que houve uma contribuição para a mudança da percepção dos professores em relação à visão da importância da utilização da informática para proporcionar melhoria no processo de ensinoaprendizagem, bem como para o aprimoramento do fazer pedagógico.

Diante das exposições dos professores e dos materiais estudados, reflete-se que não adianta mudar as ferramentas tecnológicas e continuar usando a mesma metodologia (tradicional). É necessário, por parte do professor, da gestão e da escola como um todo, haver engajamento no sentido de inovar no uso de novas tecnologias e de metodologias ativas, deslocando para o centro do processo de ensino-aprendizagem o próprio aluno.

Dado o momento atual (Pandemia Covid-19), percebe-se que é tempo de muita mudança. Assim, reafirma-se a necessidade e o compromisso assumido ao se idealizar esta intervenção pedagógica, de que o uso da tecnologia associado às metodologias ativas permite o processo de ensinoaprendizagem de forma crítica e reflexiva. Condição que leva ao exercício de uma pedagogia histórico- 
crítica, que garante melhorias do ensino pela formação de alunos com habilidades e competências para viver o protagonismo do século XXI.

\section{REFERÊNCIAS}

BACICH, L.; TANZI NETO, A.; TREVISANI, F. Ensino híbrido: personalização e tecnologia na educação. Porto Alegre: Penso, 2015.

BAUMAN, Z. Entrevista sobre a educação. Desafios pedagógicos e modernidade

Líquida. Cad. Pesqui., São Paulo, v. 39, n. 137, maio/ago. 2009. Disponível em:

https://www.scielo.br/scielo.php?script=sci_arttext\&pid=S0100-15742009000200016. Acesso em: 23 jan. 2021.

BERBEL, N. A. N. A metodologia da problematização com o Arco de Maguerez: uma reflexão teórico-epistemológica. Londrina: EdUEL, 2012.

BRASIL. Base Nacional Comum Curricular. Brasília, DF: MEC, 2018. Disponível em: http://basenacionalcomum.mec.gov.br/. Acesso em: 24 set. 2020.

CARBONELL, J. A aventura de inovar: a mudança na escola. Tradução Fátima Murad. Porto Alegre: Artmed, 2002.

COLL, C. Psicologia e currículo: uma aproximação psicopedagógica à elaboração do currículo escolar. São Paulo: Ática, 2000.

CORDÃO, F. A. Síntese da resolução CNE/CEB 1, de 3 de abril de 2002. In: BRASIL. Conselho Nacional de Educação. Câmara de Educação Básica. Síntese das diretrizes curriculares nacionais para a educação básica. 2010. Disponível em:

http://portal.mec.gov.br/index.php?option=com_docman\&view=download\&alias=32621-cnesintese-das-diretrizes-curriculares-da-educacao-basica-pdf\&Itemid=30192. Acesso em: $12 \mathrm{dez}$. 2020.

FORSTER, M. M. dos S.; FAGUNDES, M. C. V. Inovações educativas na sala de aula universitária: ruptura paradigmática/resistência ao ethos regulatório? In: REUNIÃO ANUAL DA ANPED, 29., 2006, Caxambu/MG. Anais [...]. Caxambu/MG: Anped, 2006. Disponível em:

http://29reuniao.anped.org.br/trabalhos/trabalho/GT11-1885--Int.pdf. Acesso em: 23 set. 2020.

GARCIA, F. W. A importância do uso das tecnologias no processo de ensino-aprendizagem.

Educação a Distância, Batatais, v. 3, n. 1, p. 25-48, jan./dez. 2013. Disponível em:

https://intranet.redeclaretiano.edu.br/download?caminho=upload/cms/revista/sumarios/177.pdf\&ar quivo=sumario2.pdf. Acesso em: 24 set. 2020.

LÉVY, P. Cibercultura. São Paulo: Editora 34, 1999.

MARTINS, T. M. de O.; NERY FILHO, J.; SANTOS, F. V. dos; PONTES, E. C. A gamificação de conteúdos escolares: uma experiência a partir da diversidade cultural brasileira. In: SEMINÁRIO JOGOS ELETRÔNICOS, EDUCAÇÃO E COMUNICAÇÃO, 10., abr. 2014, Salvador. Anais [...]. Salvador: UNEB, 2014. Disponível em: https://www.academia.edu/15944675/pdf. Acesso em: 23 set. 2020.

MORAN, J. M. A educação que desejamos: novos desafios e como chegar lá. 5. ed. Campinas: Papirus, 2014. 
MORAN, J. M. Metodologias ativas e modelos híbridos na educação. In: YAEGASHI, S. et al. (org.).

Novas tecnologias digitais: reflexões sobre mediação, aprendizagem e desenvolvimento.

Curitiba: CRV, 2017. p. 23-35. Disponível em: http://www2.eca.usp.br/moran/wp-

content/uploads/2018/03/Metodologias_Ativas.pdf. Acesso em: 27 out. 2020.

NÓVOA, A. Inovação para o sucesso educativo escolar. Porto Alegre: Escola

Superior de Educação, 1988.

OLIVEIRA, I.; COURELA, C. Mudança e inovação em educação: o compromisso dos professores.

Revista Interacções, v. 9, n. 27, p. 97-117, 2013. Disponível em:

https://revistas.rcaap.pt/interaccoes/article/view/3404. Acesso em: 12 dez. 2020.

POZO, J. I.; ALDAMA, C. de. A mudança nas formas de ensinar e aprender

na era digital. Átio Ensino Médio, ano 5, n. 19, fev. 2014. Disponível em:

https://www.researchgate.net/publication/319405610. Acesso em: 19 mar. 2021.

SAMPAIO, M. N.; LEITE, L. S. Alfabetização tecnológica do professor. Rio de Janeiro: Vozes, 2011.

SANTA CATARINA. Decreto n. 562, de 17 de abril de 2020. Declara estado de calamidade pública em todo o território catarinense, nos termos do COBRADE $n^{\circ}$ 1.5.1.1.0 - doenças infecciosas virais, para fins de enfrentamento à COVID-19, e estabelece outras providências. Disponível em:

https://www.legisweb.com.br/legislacao/?id=393952. Acesso em: 12 dez. 2020.

SANTA CATARINA. Secretaria de Estado da Educação. Política de educação especial.

Florianópolis: SED, 2018.

SANTOS, G. C. Kahoot!: um gameshow em sala de aula. 2016. Disponível em:

http://www.giseldacosta.com/wordpress/kahoot-um-gameshow-em-sala-de-aula/.

Acesso em: 23 set. 2020.

SAVIANI, D. Pedagogia histórico-crítica: primeiras aproximações. 9. ed. Campinas: Autores Associados, 2005.

TEDESCO, J. C. Educação e novas tecnologias: esperança ou incerteza? São Paulo: Cortez, 2004.

THIOLLENT, M. Metodologia da pesquisa-ação. São Paulo: Cortez, 2011.

TOLOMEI, B. V. A gamificação como estratégia de engajamento e motivação

na educação. Revista Científica de Educação a Distância, Rio de Janeiro, v. 7, n. 2, p. 145156, 2017. Disponível em: http://eademfoco.cecierj.edu.br/index.php/Revista/article/view/440/259. Acesso em: 23 set. 2020.

VIEGAS, A. Como o uso da tecnologia é previsto pela Base Nacional Comum Curricular (BNCC)?

Plataforma Educacional, 23 abr. 2019. Disponível em: https://www.somospar.com.br/como-ouso-da-tecnologia-e-previsto-pela-base-nacional-comum-curricular-bncc. Acesso em: 23 set. 2020.

Submissão: 15/04/2021

Aceito: 21/08/2021 
i O Guia EduTec, idealizado pelo Centro de Inovação para a Educação Brasileira (Cieb), é uma ferramenta diagnóstica, útil para a identificação de prioridades, a fim de atender efetivamente às demandas de cada rede no que concerne à utilização de tecnologias educacionais. De acordo com o Guia, o uso de tecnologia na educação deve considerar quatro elementos, que devem se integrar, em equilíbrio: visão, competência, conteúdos e recursos digitais e infraestrutura para atingir seu pleno potencial. Link para acesso: https://guiaedutec.com.br.

ii Conforme definição da Secretaria de Estado da Educação (SANTA CATARINA, 2018, p. 41), o segundo professor de turma é quem "oferece suporte e acompanhamento, nas classes regulares, ao processo de escolarização de estudantes com diagnóstico de deficiência intelectual, Transtorno do Espectro Autista e/ou deficiência múltipla, que apresentem comprometimento significativo nas interações sociais e na funcionalidade acadêmica. Esse professor atenderá também estudantes com deficiência física, matriculados nesse espaço, os quais apresentem sérios comprometimentos motores e dependência em atividades de vida prática." 